\title{
Late-Onset Post-radiation Lymphedema Provoked by Bee Venom Therapy: A Case Report
}

\author{
Young Jae Seo, MD, Yong Sung Jeong, MD, Hyo Sik Park, MD, Shin Who Park, MD, \\ Ja Young Choi, MD, Kang Jae Jung, MD, Jong Youb Lim, MD
}

Department of Rehabilitation Medicine, Eulji University Hospital, Eulji University School of Medicine, Daejeon, Korea

\begin{abstract}
Lymphedema is a common complication associated with cancer itself or with cancer treatment. Lymphedema infrequently occurs after drug therapy. Bee venom is one of the materials used in acupuncture, and it has been used in the treatment of a variety of inflammatory diseases including arthritis. We report a 74-year-old male patient with late-onset post-radiation lymphedema provoked by bee venom therapy. He was free of lymphedema for 5 years after the complete remission of prostate cancer which had been treated with transurethral resection and radiation therapy. The patient developed left leg swelling after undergoing bee venom therapy for left hip pain. Computed tomography and lymphoscintigraphy showed lymphedema without tumor recurrence or infection. The lymphatic system was suspected to be injured by bee venom therapy and lymphedema was provoked. Bee venom therapy should be used cautiously in patients prone to lymphedema.
\end{abstract}

Keywords Lymphedema, Bee venoms, Acupuncture

\section{INTRODUCTION}

Lymphedema is a condition characterized by the chronic swelling and excessive fluid retention of a limb $[1,2]$. It is a common complication usually associated with cancer itself or with cancer treatment, particularly with breast cancer treatment [1]. It is known to be uncommon in cases of prostate cancer [3]. Some risk factors of lymphedema associated with prostate cancer are lymph node dissection and additional radiation therapy
[3]. When lymphedema occurs, it is difficult to treat and often progresses, and no definite treatment has yet been established [2].

Bee venom is mostly composed of water, but it also contains various enzymes, peptides, and non-peptides, and has been studied in the treatment of inflammatory diseases and cancer [4]. Bee venom acupuncture is known to have anti-nociceptive and anti-inflammatory effects by controlling immunological and inflammatory responses through various mechanisms $[4,5]$. The exact mechanism

Received August 23, 2017; Accepted October 11, 2017

Corresponding author: Jong Youb Lim

Department of Rehabilitation Medicine, Eulji University Hospital, 95 Dunsanseo-ro, Seo-gu, Daejeon 35233, Korea. Tel: +82-42-611-3631, Fax: +82-42611-3633, E-mail: jylimmd@eulji.ac.kr

ORCID: Young Jae Seo (http://orcid.org/0000-0003-3791-5012); Yong Sung Jeong (http://orcid.org/0000-0001-9126-3866); Hyo Sik Park (http://orcid. org/0000-0002-1386-4188); Shin Who Park (http://orcid.org/0000-0002-7136-9644); Ja Young Choi (http://orcid.org/0000-0001-9829-8922); Kang Jae Jung (http://orcid.org/0000-0003-2515-4850); Jong Youb Lim (http://orcid.org/0000-0001-9100-4864).

@ This is an open-access article distributed under the terms of the Creative Commons Attribution Non-Commercial License (http://creativecommons.org/ licenses/by-nc/4.0) which permits unrestricted noncommercial use, distribution, and reproduction in any medium, provided the original work is properly cited. Copyright $\odot 2018$ by Korean Academy of Rehabilitation Medicine 
is still unknown, and the relationship between bee venom and lymphedema has not been previously reported [4]. We report a patient with late-onset post-radiation lymphedema provoked by bee venom therapy.

\section{CASE REPORT}

On January 24, 2017, a 74-year-old male patient visited the vascular surgery department because of recentlydeveloped left leg swelling. Six days prior he had felt left hip pain, and on the next day he visited a local clinic and received bee venom therapy for the first time at the left groin area. Left leg swelling developed on the following day. Vascular ultrasonography and computed tomography (CT) with angiography showed diffuse swelling of the left leg, but no evidence of vascular injury or thrombosis was found in the inguinal area or the left lower extremity (Fig. 1). Laboratory examination showed a white blood cell count of $4,880 / \mathrm{mm}^{3}$ (normal range, 3,800-10,500/ $\mathrm{mm}^{3}$ ), creatinine level of $0.70 \mathrm{mg} / \mathrm{dL}$ (normal range, $0.70-1.30 \mathrm{mg} / \mathrm{dL}$ ), albumin level of $3.6 \mathrm{~g} / \mathrm{dL}$ (normal range, 3.4-5.8 g/dL), and C-reactive protein level of 0.19 $\mathrm{mg} / \mathrm{dL}$ (normal range, $0-0.50 \mathrm{mg} / \mathrm{dL}$ ). Infection markers were normal and antibiotic therapy was not considered. A compression stocking was applied and the patient was referred to the rehabilitation department.

Upon physical examination, generalized swelling of the left whole leg without pitting was noted. The circumferences of the swollen left thigh and calf were $3 \mathrm{~cm}$ greater than those of the right side. According to a review of the patient's medical records, he had been diagnosed with prostate cancer about 5 years prior and received transurethral resection of the prostate and radiation therapy. Additionally, laparoscopic wedge resection of gastrointestinal stromal tumor was performed 4 years ago.
No specific history of conditions such as hypertension, diabetes, heart failure, and kidney disease was observed. There was also no specific family history of lymphedema, heart disease, or kidney disease. He regularly visited the urology department following the complete remission of his prostate cancer. No newly-developed tumor recurrence or distant metastasis were found upon CT. The lymph nodes of the pelvis and inguinal area showed no morphological abnormalities (Fig. 1). The prostate specific antigen (PSA) level was $0.03 \mathrm{ng} / \mathrm{mL}$ (normal range, 0-2 $\mathrm{ng} / \mathrm{mL}$ ).

Lymphoscintigraphy was performed and no lymph node activity was found in the left inguinal and iliac chains (Fig. 2). Collateral circulation or dermal backflow were not found in the left leg. Hypofunction of the lymphatic system in the left leg was suggested. He received Vitis vinifera extract (Entelon; Hanlim Pharm Co. Ltd., Seoul, Korea) at a dose of $300 \mathrm{mg} /$ day and received physical therapy from an outpatient department. However, the swelling was sustained and the leg circumference difference was $10 \mathrm{~cm}$ in the thigh and $4 \mathrm{~cm}$ in the calf.

On March 20, 2017, he was admitted to the rehabilitation department, and combined physical therapy (CPT) with manual lymphatic drainage and intermittent pneumatic compression was performed. Upon admission, laboratory examination showed a white blood cell count of $4,490 / \mathrm{mm}^{3}$, creatinine level of $0.64 \mathrm{mg} / \mathrm{dL}$, albumin level of $3.4 \mathrm{~g} / \mathrm{dL}$, and C-reactive protein level of $0.30 \mathrm{mg} /$ dL. He also received diuretics. After 10 days, the leg circumference difference decreased to $7 \mathrm{~cm}$ in the thigh and $3 \mathrm{~cm}$ in the calf. The patient was then discharged with diuretic medication. However, after 2 months, lymphedema aggravated and caused gait disturbance due to heaviness and tightness of the left leg. The leg circumference difference increased to $10 \mathrm{~cm}$ in the thigh and $7 \mathrm{~cm}$ in the calf.
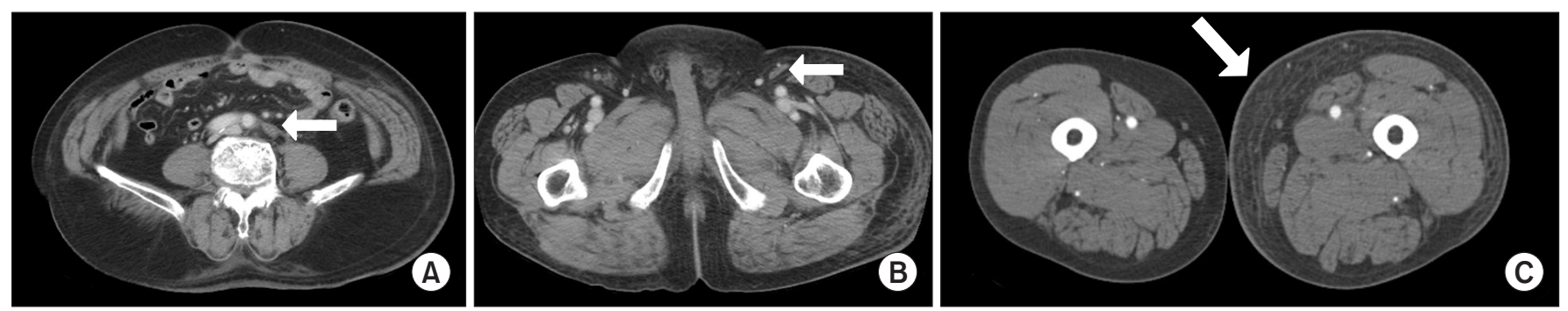

Fig. 1. Computed tomography of abdominopelvic area and both lower extremities. Normal lymph nodes (arrow) at the common iliac artery level (A) and left inguinal level (B). (C) Diffuse swelling (arrow) of the subcutaneous tissue in the left lower extremity at the thigh level. 

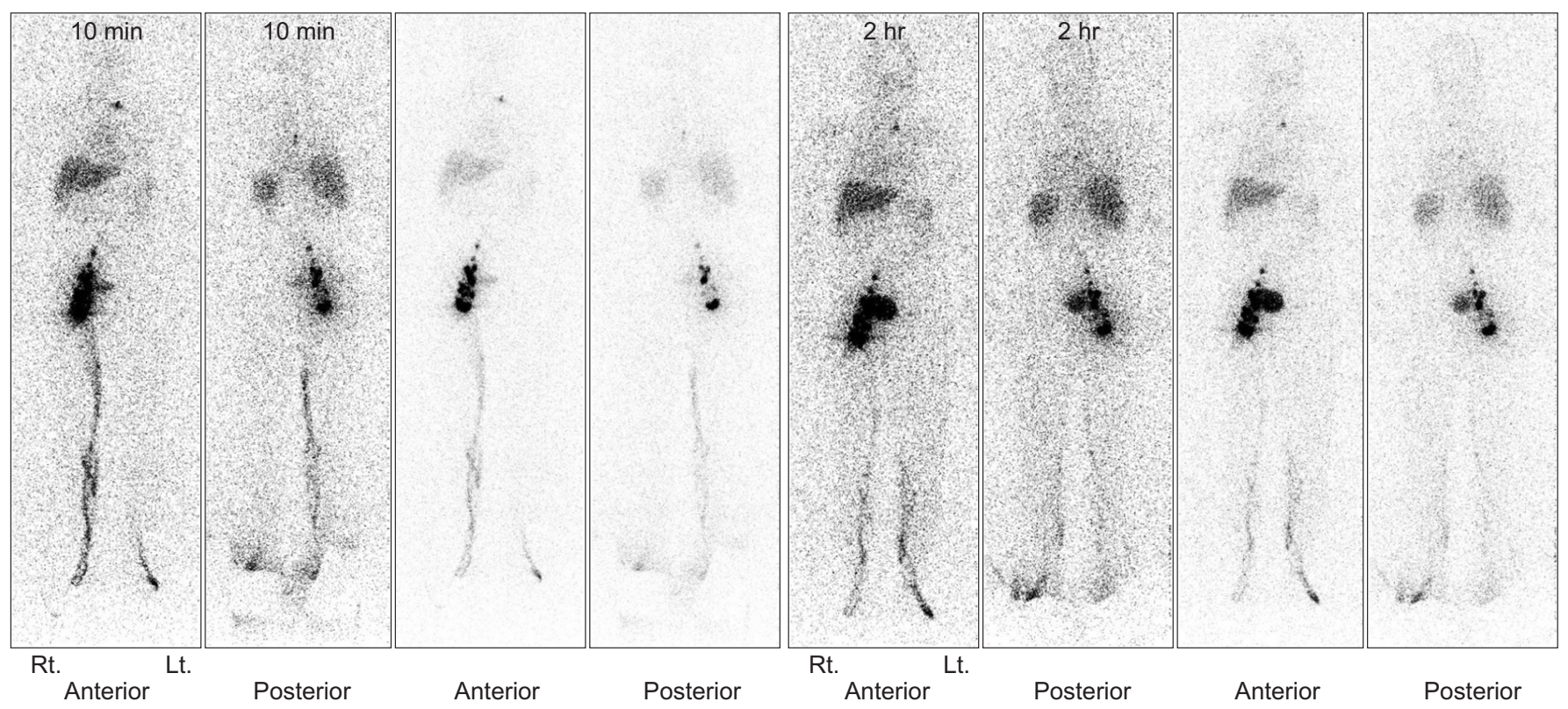

Fig. 2. Lymphoscintigraphy of both lower extremities. No lymph node activity was found in the left inguinal and iliac chains. Collateral circulation or dermal backflow in the left leg were not found.

The patient visited another hospital for additional study including a bone scan and magnetic resonance imaging, but no other diagnosis was made beyond lymphedema. Six months after onset, persistent deterioration was observed, and the patient was recommended to have lymph vessel bypass surgery, but as of the time of this writing the patient had not yet decided whether to undergo the operation.

\section{DISCUSSION}

Bee venom contains several peptide and non-peptide components, and it has been reported to be effective in relieving pain and reducing various inflammatory conditions $[4,5]$. It is known to act as an inflammatory modulator, and is widely used to treat various inflammatory diseases in Asia [6]. However, adverse effects are frequently experienced after bee venom therapy, including systemic reactions as headache, vomiting, jaundice, and local reactions such as swelling, pruritus, and localized edema [7]. These responses are thought be caused by hypersensitivity or by the active components of bee venom $[7,8]$.

This patient was free of lymphedema for 5 years after the complete remission of prostate cancer. Lymphedema was not found on abdominopelvic CT, magnetic resonance imaging, or whole-body bone scan taken during a previous routine follow-up. Lymphedema-related findings were not present in the medical records kept by the urology department until bee venom therapy. The patient reported no previous symptoms of left leg swelling. Acute allergic reactions such as respiratory failure, localized rash, and edema were not present after bee venom therapy. CT taken after lymphedema development showed normal lymph nodes in the left inguinal and iliac chains (Fig. 1). However, these lymph nodes revealed no activity on lymphoscintigraphy.

Considering these findings, normal infection markers, and normal PSA, a poorly-functioning post-radiation lymphatic system had been barely maintained and lymphedema did not develop for 5 years. The maintenance of the lymphatic system was suspected to be injured by bee venom therapy, at which point lymphedema was provoked. Although the patient did not know the method of bee venom therapy performed, a causal relationship could be suggested by the onset time. The activity of melittin (active peptide) and phospholipase A2 (enzyme) in bee venom is known to cause non-selective cytotoxicity and down-regulation of vascular endothelial growth factor (VEGF) [5,9]. Direct cytotoxicity to the weakened lymphatic circulation and inhibition of lymphangiogenesis due to VEGF down-regulation may have resulted in left leg lymphedema in this patient. Lymph- 
edema induced by interference in the intracellular pathway of the lymphatic endothelial cells by reducing VEGF production was reported in a renal transplant recipient treated with everolimus medication [10].

Even though constant CPT and diuretic therapy were performed following only one session of bee venom therapy, the patient's lymphedema continued to worsen. According to a previous study, use of radiation therapy, lymph node status, infection, obesity, and old age each independently increase the risk of lymphedema [1]. In this patient, the persistence of lymphedema might be caused by old age and the patient's history of radiation therapy. These factors possibly inhibited the sufficient recovery of the lymphatic circulation, and thus lymphatic fluid had gradually accumulated.

To the best of the authors' knowledge, lymphedema provoked by bee venom therapy has not been previously reported. This case showed that bee venom damaged the lymphatic system and caused lymphedema. Bee venom therapy should be used with caution in the future in patients prone to lymphedema. Further studies are needed to confirm our findings and reveal the exact mechanism of lymphedema induced by bee venom.

\section{CONFLICT OF INTEREST}

No potential conflict of interest relevant to this article was reported.

\section{REFERENCES}

1. Cassileth BR, Van Zee KJ, Yeung KS, Coleton MI, Cohen $\mathrm{S}$, Chan $\mathrm{YH}$, et al. Acupuncture in the treatment of upper-limb lymphedema: results of a pilot study. Cancer 2013;119:2455-61.

2. Li L, Yuan L, Chen X, Wang Q, Tian J, Yang K, et al. Current treatments for breast cancer-related lymphoedema: a systematic review. Asian Pac J Cancer Prev 2016;17:4875-83.

3. Keegan KA, Cookson MS. Complications of pelvic lymph node dissection for prostate cancer. Curr Urol Rep 2011;12:203-8.

4. Hossen MS, Shapla UM, Gan SH, Khalil MI. Impact of bee venom enzymes on diseases and immune responses. Molecules 2016;22:25.

5. Orsolic N. Bee venom in cancer therapy. Cancer Metastasis Rev 2012;31:173-94.

6. Ahn YJ, Shin JS, Lee J, Lee YJ, Kim MR, Shin YS, et al. Safety of essential bee venom pharmacopuncture as assessed in a randomized controlled double-blind trial. J Ethnopharmacol 2016;194:774-80.

7. Park JH, Yim BK, Lee JH, Lee S, Kim TH. Risk associated with bee venom therapy: a systematic review and meta-analysis. PLoS One 2015;10:e0126971.

8. Abdulsalam MA, Ebrahim BE, Abdulsalam AJ. Immune thrombocytopenia after bee venom therapy: a case report. BMC Complement Altern Med 2016;16:107.

9. Huh JE, Baek YH, Lee MH, Choi DY, Park DS, Lee JD. Bee venom inhibits tumor angiogenesis and metastasis by inhibiting tyrosine phosphorylation of VEGFR-2 in LLC-tumor-bearing mice. Cancer Lett 2010;292:98110.

10. Ersoy A, Koca N. Everolimus-induced lymphedema in a renal transplant recipient: a case report. Exp Clin Transplant 2012;10:296-8. 